\title{
Influenza Virus Evolution, Host Factors and the Assessment of Influenza Vaccine Effectiveness
}

\author{
Monika Redlberger-Fritz ${ }^{1 *}$, Michael Kundi ${ }^{2}$ and Theresia Popow-Kraupp ${ }^{1}$ \\ ${ }^{1}$ Department of Virology, Medical University Vienna, Vienna, Austria \\ ${ }^{2}$ Institute of Environmental Health, Centre for Public Health, Medical University Vienna, Austria \\ *Corresponding author: Monika Redlberger-Fritz, Department of Virology, Medical University Vienna, Vienna, Austria, Tel: +43140160-65515; E-mail: \\ monika.redlberger@meduniwien.ac.at
}

Received date: May 19, 2016; Accepted date: June 13, 2016; Published date: June 15, 2016

Copyright: (c) 2016 Redlberger-Fritz M, et al. This is an open-access article distributed under the terms of the Creative Commons Attribution License, which permits unrestricted use, distribution, and reproduction in any medium, provided the original author and source are credited.

\begin{abstract}
For over 10 years, the test-negative case-control design is used for a timely and reliable estimation of seasonal influenza vaccine performance. Influenza vaccine effectiveness (VE) varies significantly by influenza type and subtype. Therefore, the calculation of type/subtype specific VE estimates is essential, as the calculation of an overall protective effect could be misleading if several types are circulating. Besides viral factors, also host and environmental factors influence the protective effect of influenza vaccines considerably. Rising evidence suggests that repeated vaccination using the identical vaccine in successive seasons combined with the circulation of relevant drift variants negatively interferes with the protection provided by the vaccine. For a better understanding of factors influencing VE, it is important to combine genetic, antigenic, epidemiologic and clinical data with agent-host factors for optimizing VE estimates.
\end{abstract}

\section{Short Communication}

Influenza virus vaccines are the main prophylactic strategy for reducing the burden of influenza morbidity and mortality [1]. Nevertheless the currently available influenza vaccines induce a narrow and strain specific immunity and their protective effect is limited by the continuous evolution of influenza viruses associated with rapidly evolving mutations in key antigenic sites of the hemagglutinin surface protein [2-5]. Besides viral factors, also host and environmental factors considerably influence the protective effect of influenza vaccines considerably [6-8]. Assessment of vaccine effectiveness (VE) using the test-negative case-control design has revolutionized VE monitoring and has contributed to a better understanding of suboptimal VE of seasonal influenza vaccines [9]. This methodology first described for the 2004/05 influenza season in Canada $[10,11]$ is now the preferred observational study design to reliably calculate the effectiveness of seasonal influenza vaccines against medically attended influenza virus infections [12]. The method relies on a sentinel surveillance network of physicians collecting clinical data and specimens from patients with influenza like illness. Its prospective nature allows early interim estimates of VE during the season [13-15]. Linking the clinical data of the participating patients to data of the antigenic and genetic characterization of viruses recovered from these study patients have revealed substantial variations in $\mathrm{VE}$ estimates across types and subtypes [11,12,16-18].

Although it is appealing to report an average protective effect of influenza vaccination, evidence suggests that estimates of an overall influenza vaccine effectiveness can be misleading especially in seasons with a heterogeneous mix of strains and/or influenza virus strains of different types and subtypes evolving during a season $[12,19,20]$. The findings of our study [17] on estimates of influenza vaccine effectiveness in 2014/15 in Austria, where influenza vaccine provided substantial protection against $\mathrm{A}(\mathrm{H} 1 \mathrm{~N} 1) \mathrm{pdm} 09$ and influenza $\mathrm{B}$ viruses, but only very limited protection against $\mathrm{A}(\mathrm{H} 3 \mathrm{~N} 2)$ viruses, underscore the importance to perform type/subtype specific VE estimates.

This is particularly important for the $\mathrm{A}(\mathrm{H} 3 \mathrm{~N} 2)$ viruses because they are the most rapidly evolving influenza viruses and it is therefore not surprising, that their rapid antigenic drift regularly contributes to reduced VE [18,21-23]. Another aspect in this context is the decrease of the protective effect of seasonal influenza vaccines against $\mathrm{A}(\mathrm{H} 3 \mathrm{~N} 2)$ virus infections during the season as indicated by reduced VE estimates in the second part of the season reported in some studies [24-26]. One possible explanation provided by the authors of these studies was the waning of vaccine-induced immunity during the season. In these studies detailed monitoring of the evolution of the influenza $\mathrm{A}(\mathrm{H} 3 \mathrm{~N} 2)$ virus strains collected from study participants has not been performed and therefore the significant influence of viral changes during the season on VE estimates has not been addressed. The changing dynamics of circulating strains with variable matches to the vaccine strains during the season on VE estimates is further substantiated by our recently published assessment of VE in Austria [17]. The results of our study clearly demonstrate that the calendar week of infection was the factor that influenced VE estimates most. The increasing VE estimates in the second part of the season correlated with the increased circulation of influenza virus strains with a better match to the vaccine strains as only revealed by detailed genetic monitoring of the circulating virus strains. Antigenic characterization by conventional hemagglutination inhibition (HI) assay failed to detect the relevant $\mathrm{A}(\mathrm{H} 3 \mathrm{~N} 2)$ drift variants in time, due to the unavailability of antisera during the season against the newly evolving viruses. In addition $\mathrm{A}(\mathrm{H} 3 \mathrm{~N} 2)$ viruses increasingly fail to agglutinate red blood cells [27] and so the development of alternative methods for antigenic characterization becomes crucial. Meanwhile, only the genomic analyses can provide timely and reliable virus characterization data for $\mathrm{A}(\mathrm{H} 3 \mathrm{~N} 2)$ viruses, but reliable genetic correlates for relevant antigenic 
mutations have still to be defined. This shows again the importance of the inclusion of genetic data in VE-estimate studies.

In addition, the performance of seasonal influenza vaccines is not only influenced by viral diversity and evolution, but also by different host factors like the patient's age, concomitant and underlying diseases. Also the individual history of infections and/or vaccinations plays an important role in the patientt's immune response [3,6-8,28-31]. In particular, several studies have recently reported that frequent prior vaccination is associated with sub optimal vaccine effectiveness $[3,29,30,32]$. In these studies, a negative interference from prior immunisation with current vaccine protection was observed. This was especially pronounced in seasons with the circulation of relevant drift variants and repeated immunisation with an identical (but mismatched) vaccine antigen. This negative interference with current vaccine protection is impressively demonstrated by the recent study for the 2014/15 season in Canada of Skowronski et al. [3]. In this study patients without vaccination in season 2013/14 had significant protection against $\mathrm{A}(\mathrm{H} 3 \mathrm{~N} 2)$ illness, whereas patients that had received the identical vaccine in $2013 / 14$ and $2014 / 15$ had a significantly reduced protection against $\mathrm{A}(\mathrm{H} 3 \mathrm{~N} 2)$ infections.

In our study, we were not able to reliably address this issue, since the majority of the participants $(94 \%)$ had not received influenza vaccination for the previous season 2013/14 and therefore the group of participants immunized in both season was too small to allow further analyses.

Nevertheless investigating the influence of previous vaccination with seasonal influenza vaccines on the protective effect of the current influenza vaccine is a very important issue. To our knowledge only, one recently published study on VE estimates using the test-negative casecontrol design did stratify by the type of influenza vaccines used (inactivated vs. live attenuated influenza vaccines) [33]. Since the immune response induced by live attenuated vaccines differ significantly in many aspects (immune repertoire, its functionality, magnitude and longevity) from the immune response induced by inactivated vaccines [34-36] the type of vaccine used may be an important influencing factor on VE estimates. Detailed comparative analyses on the protective effect of inactivated and live attenuated influenza vaccines in different age groups are required for a better understanding of influenza vaccine performance and interference. Regarding the increasing use of live attenuated influenza vaccines in children and young adults, this will become all the more important, especially in the context of interference of prior immunization with current vaccine protection. In future it will become necessary to stratify VE estimates by type of influenza vaccine used (inactivated $v s$. life attenuated influenza vaccines) to increase our knowledge on influenza vaccine performance.

In addition to the type of vaccines used a variety of host, epidemiological and viral factors exert an influence on the assessment of influenza VE. Therefore, standardised recommendations for testnegative design studies as summarised in Table 1 are required to minimise biases and to obtain precise and comparable results for influenza vaccine performance. Furthermore, increasing sample sizes will allow more precise estimates of age group and subtype specific VE and will pave the way to estimate the performance of different types of vaccines used.

In summary, the test-negative design is currently the most reliable approach for routine assessment of influenza VE against medically attended influenza virus infection. It is much less susceptible to bias due to misclassification of infection and to confounding by health care seeking behaviour compared to traditional cohort studies or casecontrol studies.

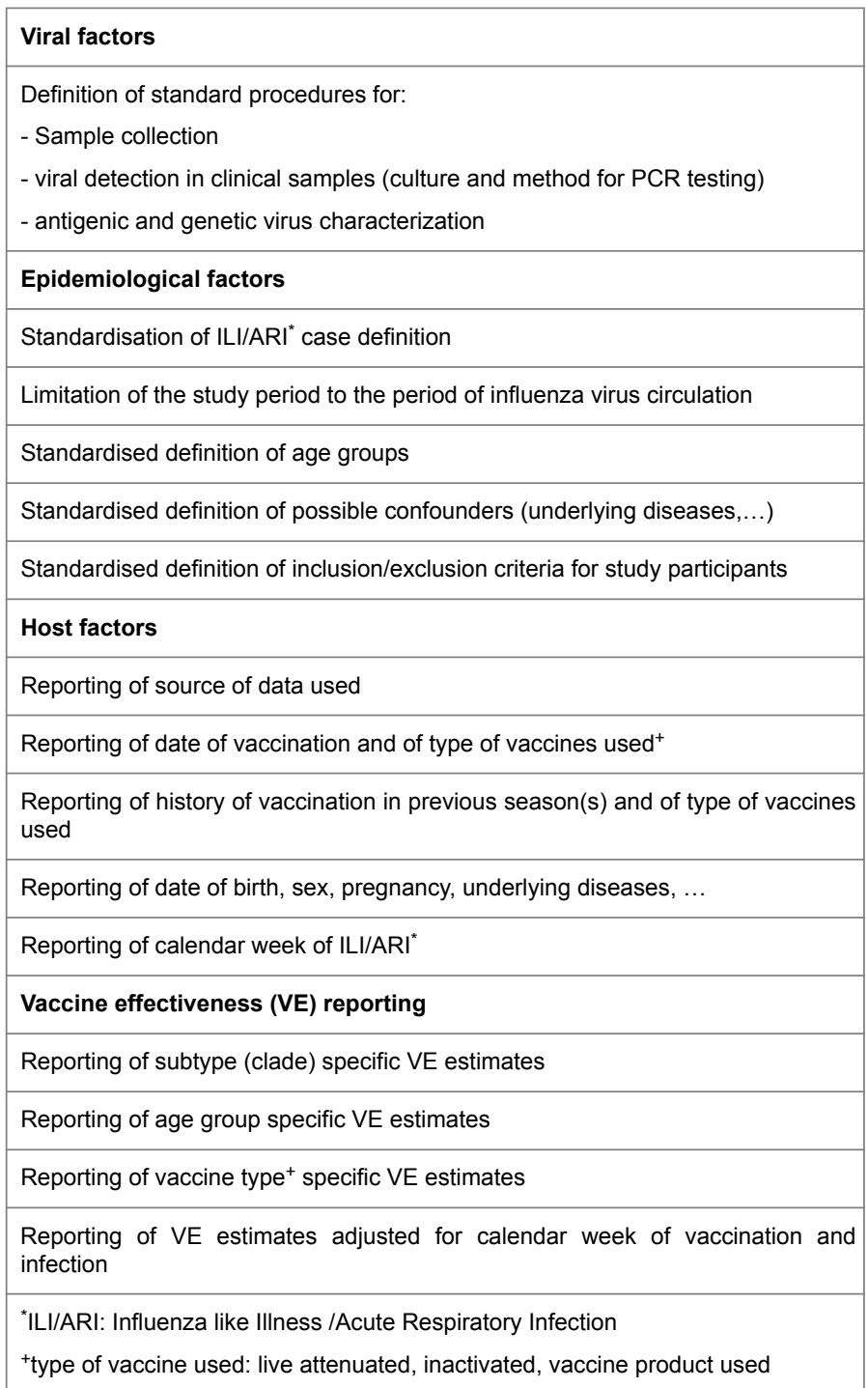

Table 1: Recommendation for the standardization of influenza vaccine effectiveness studies using the test-negative case control design concerning factors that should be considered.

It is a feasible and easily to implement approach to obtain influenza VE estimates. An additional advantage of this study design is that vaccine performance can be prospectively as well as retrospectively assessed. The statistical methods used to estimate VE in test-negative case control studies have also been developing from crude estimates as used in the first studies to the now applied methods of multivariate logistic regression and propensity score models [37]. In addition, the use of conditional logistic regression matching on time can provide better fit especially if vaccine uptake extends over a season [38]. Further research, however, is needed for optimizing the set of confounders to be considered. Special attention should be payed to the number and type of present and previously received vaccinations and the time since last vaccination. Another aspect that needs further study is the test of the assumption that the incidence of non-influenza 
respiratory infections is equal between vaccinated and unvaccinated groups within strata of care-seeking patients [19].

\section{Conclusion}

For a better understanding of factors influencing the protective effect of influenza vaccines, it is crucial to combine detailed genetic, antigenic, epidemiologic data and information on vaccine type used with agent-host factors for optimizing VE estimates.

\section{References}

1. Leung VK, Cowling BJ, Feng S, Sullivan SG (2016) Concordance of interim and final estimates of influenza vaccine effectiveness: a systematic review. Euro surveillance: bulletin Europeen sur les maladies transmissibles $=$ European communicable disease bulletin 21 .

2. Skowronski DM, Sabaiduc S, Chambers C, Eshaghi A, Gubbay JB, et al. (2016) Mutations acquired during cell culture isolation may affect antigenic characterisation of influenza $\mathrm{A}(\mathrm{H} 3 \mathrm{~N} 2)$ clade $3 \mathrm{C} .2 \mathrm{a}$ viruses Euro surveillance: bulletin Europeen sur les maladies transmissibles = European communicable disease bulletin 21 .

3. Skowronski DM, Chambers C, Sabaiduc S, De Serres G, Winter AL, et al. (2016) A Perfect Storm: Impact of Genomic Variation and Serial Vaccination on Low Influenza Vaccine Effectiveness During the 2014-2015 Season. Clinical infectious diseases: an official publication of the Infectious Diseases Society of America.

4. Koel BF, Burke DF, Bestebroer TM, van der Vliet S, Zondag GC, et al. (2013) Substitutions near the receptor binding site determine major antigenic change during influenza virus evolution. Science 342: 976-979.

5. Koel BF, Mögling R, Chutinimitkul S, Fraaij PL, Burke DF, et al. (2015) Identification of amino acid substitutions supporting antigenic change of influenza A(H1N1)pdm09 viruses. J Virol 89: 3763-3775.

6. Govaert TM, Thijs CT, Masurel N, Sprenger MJ, Dinant GJ, et al. (1994) The efficacy of influenza vaccination in elderly individuals. A randomized double-blind placebo-controlled trial. JAMA 272: 1661-1665.

7. Remschmidt C, Wichmann O, Harder $T$ (2015) Vaccines for the prevention of seasonal influenza in patients with diabetes: systematic review and meta-analysis. BMC Med 13: 53.

8. Loubet P, Loulergue P, Galtier F, Launay O (2016) Seasonal influenza vaccination of high-risk adults. Expert Rev Vaccines .

9. Fielding JE (2016) Methodological evolution of influenza vaccine effectiveness assessment. Lancet Infect Dis .

10. Skowronski DM, Gilbert M, Tweed SA, Petric M, Li Y, et al. (2005) Effectiveness of vaccine against medical consultation due to laboratoryconfirmed influenza: results from a sentinel physician pilot project in british columbie, 2004-2005. Can Comm Dis Rep 31: 181-190.

11. Skowronski DM, Masaro C, Kwindt TL, Mak A, Petric M, et al. (2007) Estimating vaccine effectiveness against laboratory-confirmed influenza using a sentinel physician network: results from the 2005-2006 season of dual A and B vaccine mismatch in Canada. Vaccine 25: 2842-2851.

12. Belongia EA, Simpson MD, King JP, Sundaram ME, Kelley NS, et al. (2016) Variable influenza vaccine effectiveness by subtype: a systematic review and meta-analysis of test-negative design studies. Lancet Infect Dis .

13. Pebody RG, Warburton F, Ellis J, Andrews N, Thompson C, et al. (2015) Low effectiveness of seasonal influenza vaccine in preventing laboratoryconfirmed influenza in primary care in the United Kingdom: 2014/15 mid-season results. Euro Surveill 20: 21025.

14. Chambers C, Skowronski DM, Sabaiduc S, Winter AL, Dickinson JA, et al. (2016) Interim estimates of 2015/16 vaccine effectiveness against influenza $\mathrm{A}(\mathrm{H} 1 \mathrm{N1}) \mathrm{pdm} 09$, Canada, February 2016. Euro surveillance : bulletin Europeen sur les maladies transmissibles = European communicable disease bulletin 21 .

15. Pebody R, Warburton F, Ellis J, Andrews N, Potts A, et al. (2016) Effectiveness of seasonal influenza vaccine in preventing laboratory- confirmed influenza in primary care in the United Kingdom: 2015/16 mid-season results. Euro surveillance : bulletin Europeen sur les maladies transmissibles = European communicable disease bulletin 21 .

16. Skowronski DM, Chambers C, Sabaiduc S, De Serres G, Winter AL, et al. (2015) Integrated Sentinel Surveillance Linking Genetic, Antigenic, and Epidemiologic Monitoring of Influenza Vaccine-Virus Relatedness and Effectiveness During the 2013-2014 Influenza Season. J Infect Dis 212: 726-739.

17. Redlberger-Fritz M, Kundi M, Popow-Kraupp T (2016) Detailed Report on 2014/15 Influenza Virus Characteristics, and Estimates on Influenza Virus Vaccine Effectiveness from Austria's Sentinel Physician Surveillance Network. PLoS One 11: e0149916.

18. Skowronski DM, Janjua NZ, De Serres G, Sabaiduc S, Eshaghi A, et al. (2014) Low 2012-13 influenza vaccine effectiveness associated with mutation in the egg-adapted $\mathrm{H} 3 \mathrm{~N} 2$ vaccine strain not antigenic drift in circulating viruses. PLoS One 9: e92153.

19. Jackson ML, Nelson JC (2013) The test-negative design for estimating influenza vaccine effectiveness. Vaccine 31: 2165-2168.

20. Foppa IM, Haber M, Ferdinands JM, Shay DK (2013) The case testnegative design for studies of the effectiveness of influenza vaccine. Vaccine 31: 3104-3109.

21. Kissling E, Valenciano M, Buchholz U, Larrauri A, Cohen JM, et al. (2014) Influenza vaccine effectiveness estimates in Europe in a season with three influenza type/subtypes circulating: the I-MOVE multicentre case-control study, influenza season 2012/13. Euro Surveill 19.

22. Bedford T, Suchard MA, Lemey P, Dudas G, Gregory V, et al. (2014) Integrating influenza antigenic dynamics with molecular evolution. See comment in PubMed Commons below Elife 3: e01914.

23. Smith DJ, Lapedes AS, de Jong JC, Bestebroer TM, Rimmelzwaan GF, et al. (2004) Mapping the antigenic and genetic evolution of influenza virus. Science 305: 371-376.

24. Kissling E, Valenciano M, Larrauri A, Oroszi B, Cohen JM, et al. (2013) Low and decreasing vaccine effectiveness against influenza $A(H 3)$ in 2011/12 among vaccination target groups in Europe: results from the IMOVE multicentre case-control study. Euro Surveill 18.

25. Kissling E, Nunes B, Robertson C, Valenciano M, Reuss A, et al. (2016) IMOVE multicentre case-control study 2010/11 to 2014/15: Is there within-season waning of influenza type/subtype vaccine effectiveness with increasing time since vaccination? Euro surveillance 21: p-30201.

26. Gherasim A, Pozo F, de Mateo S, Aspiritxaga Gamarra I, García-Cenoz $\mathrm{M}$, et al. (2016) Waning protection of influenza vaccine against mild laboratory confirmed influenza A(H3N2) and B in Spain, season 2014-15. Vaccine 34: 2371-2377.

27. Lin Y, Gu Y, Wharton SA, Whittaker L, Gregory V, et al. (2015) Optimization of a micro-neutralisation assay and its application in antigenic characterisation of influenza viruses. Influenza Other Respir Viruses.

28. Fonville JM, Wilks SH, James SL, Fox A, Ventresca M, et al. (2014) Antibody landscapes after influenza virus infection or vaccination. Science 346: 996-1000.

29. McLean HQ, Thompson MG, Sundaram ME, Meece JK, McClure DL, et al. (2014) Impact of repeated vaccination on vaccine effectiveness against influenza $\mathrm{A}(\mathrm{H} 3 \mathrm{~N} 2)$ and $\mathrm{B}$ during 8 seasons. Clin Infect Dis 59: 1375-1385.

30. Ohmit SE, Thompson MG, Petrie JG, Thaker SN, Jackson ML, et al. (2014) Influenza vaccine effectiveness in the 2011-2012 season: protection against each circulating virus and the effect of prior vaccination on estimates. Clin Infect Dis 58: 319-327.

31. Smith DJ, Forrest S, Ackley DH, Perelson AS (1999) Variable efficacy of repeated annual influenza vaccination. Proc Natl Acad Sci USA 96: 14001-14006.

32. Skowronski DM, Chambers C, Sabaiduc S, De Serres G, Dickinson JA, et al. (2015) Interim estimates of 2014/15 vaccine effectiveness against influenza $\mathrm{A}(\mathrm{H} 3 \mathrm{~N} 2)$ from Canada's Sentinel Physician Surveillance Network, January 2015. Euro Surveill 20: p-21022. 
Citation: Redlberger-Fritz M, Kundi M, Popow-Kraupp T (2016) Influenza Virus Evolution, Host Factors and the Assessment of Influenza Vaccine Effectiveness. J Vaccines Vaccin 7: 325. doi:10.4172/2157-7560.1000325

Page 4 of 4

33. Gaglani M, Pruszynski J, Murthy K, Clipper L, Robertson A, et al. (2016) Influenza Vaccine Effectiveness Against 2009 Pandemic Influenza A(H1N1) Virus Differed by Vaccine Type During 2013-2014 in the United States. J Infect Dis 213: 1546-1556.

34. Pulendran B, Oh JZ, Nakaya HI, Ravindran R, Kazmin DA (2013) Immunity to viruses: learning from successful human vaccines. Immunol Rev 255: 243-255.

35. Mohn KG, Bredholt G, Brokstad KA, Pathirana RD, Aarstad HJ, et al. (2015) Longevity of B-cell and T-cell responses after live attenuated influenza vaccination in children. J Infect Dis 211: 1541-1549.
36. Krammer F, Palese P (2015) Advances in the development of influenza virus vaccines. Nat Rev Drug Discov 14: 167-182.

37. Sullivan SG, Feng S, Cowling BJ (2014) Potential of the test-negative design for measuring influenza vaccine effectiveness: a systematic review. Expert Rev Vaccines 13: 1571-1591.

38. Bond HS, Sullivan SG, Cowling BJ (2016) Regression approaches in the test-negative study design for assessment of influenza vaccine effectiveness. Epidemiol Infect 144: 1601-1611. 